ARTIGOS

\title{
A comunidade científica de Alagoas: um olhar a partir dos seus grupos de pesquisa ${ }^{1}$
}

\section{The scientific community of Alagoas: an analysis based on its research groups}

(i) Universidade Federal do Amazonas - UFAM, Manaus, AM, Brasil. http://orcid.org/0000-0002-

2348-9350,ferreira.camilasilva@gmail.com.

(ii) Universidade Federal do Rio Grande do Sul - UFRGS, Porto Alegre, RS, Brasil.

http://orcid.org/0000-0002-7047-4530, rlopes@gmail.com.

\begin{abstract}
Resumo:
No contexto da expansão e diversificação do Ensino Superior brasileiro, o presente texto busca aproximar-se de um tema parcamente explorado na literatura nacional: a relação entre a dilatação deste grau de ensino e a construção e o fortalecimento das comunidades científicas nos estados da federação. O caso alagoano é tomado à análise, com vistas a compreender o desenvolvimento de sua comunidade científica nas duas últimas décadas. Trabalhamos, para tanto, com dados compilados e difundidos pelo Diretório de Grupos de Pesquisa do Conselho Nacional de Desenvolvimento Científico e Tecnológico, com os quais elaboramos uma caracterização capaz de oferecer suporte para a objetivação da prática da pesquisa e da formação de novos pesquisadores. A experiência alagoana expressa, pois, questões nacionais e locais de forma concomitante, de maneira que seu estudo implica um olhar relacional sobre as reconfigurações recentes do desenvolvimento da ciência no país.
\end{abstract}

Palavras-chave: comunidade científica, expansão, Ensino Superior, Alagoas

\footnotetext{
${ }^{1}$ Normalização, preparação e revisão textual: Douglas Mattos (Tikinet) - revisao@tikinet.com.br
} 


\title{
pro.posıções
}

$e$-ISSN 1980-6248

http://dx.doi.org/10.1590/1980-6248-2018-0086

\begin{abstract}
:
In the context of the expansion and diversification of Brazilian Higher Education, this paper approaches a theme that has been poorly explored in the national literature: the relationship between the expansion of this educational level and the construction and strengthening of the scientific communities in the states of the country. We analyzed the case of Alagoas aiming to understand the development of its scientific community in the last two decades. We work with data compiled and disseminated by the Directory of Research Groups of Conselho Nacional de Desenvolvimento Cientifico e Tecnologico, based on which we elaborated a characterization capable of providing a support for the objectification of research practice and the training of new researchers. Therefore, the Alagoas experience concomitantly expresses national and local issues, so its study implies a relational look at the recent reconfigurations of the development of science in the country.
\end{abstract}

Keywords: scientific community, expansion, Higher Education, Alagoas

\section{Introdução}

No cenário do Ensino Superior brasileiro, as últimas décadas têm sido marcadas por acentuadas transformações que abrangem, entre outros aspectos, a incorporação cada vez mais alargada de novos públicos por meio da expansão do número de instituições e de sujeitos (Martins, 2000; Neves, 2003; Zago, 2006). Os processos de expansão, contudo, não podem ser entendidos de forma linear ou homogênea em todo o país. Mesmo submetido à regulamentação nacional, que permite certa amplitude institucional, administrativa e didática, o próprio Ensino Superior brasileiro é resultado de experiências particularizadas em função das condições de materialidade deste grau de ensino. Localização geográfica, instituições de diversas naturezas e com diferentes dependências administrativas, professores e públicos distintos constituem expressões da heterogeneidade de formas sob as quais o Ensino Superior se apresenta no Brasil.

O presente artigo situa-se no panorama empírico do crescimento e da diversidade de configurações do Ensino Superior. Interessa-nos aqui correlacionar o fenômeno do alargamento e da diversificação deste nível de ensino com o desenvolvimento da prática de pesquisa no Brasil e, mais particularmente, no estado de Alagoas, e da comunidade científica, objetivadas aqui por meio dos grupos de pesquisa. Neste sentido, nosso objetivo consiste em analisar o desenvolvimento da comunidade científica do estado de Alagoas nas duas últimas décadas, 


\section{pro.posıções}

http://dx.doi.org/10.1590/1980-6248-2018-0086

\section{$e$-ISSN 1980-6248}

através dos dados relativos aos grupos de pesquisa e tendo como pano de fundo os processos de expansão e diversificação do Ensino Superior brasileiro.

O exercício de objetivar um estado brasileiro, no âmbito do desenvolvimento de sua comunidade científica, significa lançar um olhar relacional entre as realidades local e nacional. A experiência alagoana no quesito da pesquisa universitária denota, de um lado, as especificidades do lugar e, de outro, o alcance do Estado e das políticas públicas no delineamento do que estamos chamando de comunidade de agentes que se ocupam da prática de pesquisa e de construção e divulgação de conhecimento. $\mathrm{O}$ caso alagoano expressa o desenvolvimento do Ensino Superior e da pesquisa em um estado com uma história relativamente recente no que toca à escolarização superior e nos auxilia a compreender o papel das instituições de Ensino Superior (IES) na constituição de uma comunidade científica.

Do ponto de vista metodológico, destaca-se a utilização de mixed methods (Creswell, 2012) com vistas a combinar as abordagens quantitativa e qualitativa. A operacionalização do estudo foi realizada a partir do trabalho com os dados do Diretório dos Grupos de Pesquisa do Conselho Nacional de Desenvolvimento Científico e Tecnológico (DGP/CNPq). Este diretório cumpre o papel de inventário dos grupos de pesquisa científica e tecnológica em atividade no país e é constantemente utilizado como base para estudos e reflexões acerca dos grupos de pesquisa do país, seus recursos humanos, linhas e especialidades, produção e parcerias desenvolvidas (Lopes \& Lobo, 2016; Oliveira \& Silva, 2014; Rapini, 2007).

Em um primeiro momento, nos ocuparemos de uma reflexão em torno do que estamos a denominar de comunidade científica alagoana, por meio de um diálogo entre os aspectos conceituais e as condições sócio-históricas que possibilitaram a construção desta comunidade destaca-se, nesta frente de discussão, o caráter recente tanto do desenvolvimento do Ensino Superior em Alagoas quanto dos espaços de investigação institucionalizados, a exemplos dos programas de pós-graduação e dos grupos de pesquisa. Logo depois, na segunda parte do texto, o viés longitudinal ganha relevo com vistas a oferecer um mapeamento dos grupos de pesquisa no estado aqui analisado. São duas as frentes de debate que marcam os desdobramentos deste exercício de mapear, a saber: a faceta institucional e a faceta das áreas do conhecimento. 


\section{pro.posições}

http://dx.doi.org/10.1590/1980-6248-2018-0086

$e$-ISSN 1980-6248

\section{Alagoas e a constituição recente de sua comunidade científica}

As transformações ocorridas a partir da década de 1990 na estrutura universitária do Brasil criaram as possibilidades de fortalecimento da ciência desenvolvida no país. Um dos elementos desencadeados por tal processo diz respeito à constituição e à paulatina consolidação de uma "comunidade científica". O uso das aspas neste termo demarca um debate em torno da conceituação do conjunto de instituições e agentes envolvidos na construção e difusão de conhecimento científico, no funcionamento do campo em si e na formação de seus novos quadros. Alguns autores sublinham as limitações deste constructo pela ideia de harmonia que impregna o vocábulo "comunidade", o que acaba por calar a heterogeneidade e as lutas que marcam o campo científico, mistificando este espaço social (Bourdieu, 2008; Hey, 2008; Sousa, 2010).

Tendo em consideração este debate de âmbito conceitual, utilizamos aqui a noção de comunidade científica para tratar dos agentes e instituições que atuam e conferem forma ao espaço dedicado à ciência no interior do campo científico brasileiro e, mais precisamente, alagoano. Neste sentido, entendemos que o próprio conceito de comunidade, sendo historicamente situado, é atravessado pela crescente diferenciação social e carrega as disputas do todo no funcionamento de determinada esfera da vida em sociedade. Portanto, o uso do termo "comunidade científica", neste trabalho, refere-se a um campo que funciona sob uma lógica própria com todas as suas contradições, heterogeneidades, dominações e lutas, as quais envolvem diferentes agentes situados em posições distintas neste espaço social.

Para isto, do ponto de vista da mirada selecionada para o presente estudo, nos afastamos um pouco dos detalhes analíticos pormenorizados, tais como trajetórias dos grupos de pesquisa, características dos grupos que compõem a comunidade científica alagoana etc., e ajustamos o foco para compreensão de uma dimensão mais ampla do processo, qual seja: da constituição e desenvolvimento desta comunidade, através da institucionalização da prática de pesquisa em contextos universitários.

A prática de pesquisa científica, no Brasil, está intimamente ligada à instituição universitária. Isso porque o modelo de Ensino Superior que o país adotou desde a Reforma de 1968, com a Lei no 5.540, de 28 de novembro de 1968, tem como pressuposto que a pesquisa científica está a cargo primordialmente das universidades. E, ao mesmo tempo, para ser considerada universitária, uma instituição necessita desenvolver atividades de ensino, pesquisa 


\section{pro.posıções}

e-ISSN 1980-6248

http://dx.doi.org/10.1590/1980-6248-2018-0086

e extensão. Esta consideração será corroborada pelos dados apresentados mais adiante. No contexto brasileiro, "o campo acadêmico é entendido como o lócus onde ocorrem práticas institucionalizadas de produção do conhecimento, o que envolve sobretudo a ideia de universidade" (Hey, 2008, p. 16).

Assim, num contexto em que o Ensino Superior foi se ampliando, suas atividades também acompanharam a dilatação, seja por meio do polo do ensino com a criação de novos cursos e de novas vagas, seja através do polo da pesquisa com o fortalecimento e a constituição de novos grupos de pesquisa, seja ainda pelo pilar da extensão e dos projetos que o sustentam.

No que tange especificamente ao caso alagoano, a sua história no âmbito do Ensino Superior - com as condições de possibilidade de constituição, crescimento e da recente expansão e consolidação das instituições neste estado - é fundamental para a compreensão do espaço dos possíveis, que nos permite falar atualmente em uma comunidade científica alagoana.

A existência de instituições com características pós-secundárias remonta ao início do século XX em Alagoas. A principal preocupação para formação de terceiro grau à época era a formação de uma elite eclesiástica e burocrática que pudesse ocupar os cargos no interior do estado que recém se estruturara. É apenas na segunda metade desse século que o cenário alagoano de IES começa a se diferenciar, a partir do aparecimento de iniciativas mais sistemáticas de criação e organização de instituições de terceiro grau - são os casos das faculdades de Medicina (1951) e de Filosofia (1952)².

A criação e consolidação dessas iniciativas têm relação com o processo de urbanização que atravessou a capital alagoana, Maceió, a partir de 1950, e com a diferenciação da elite rural-canavieira para o início da formação de grupos urbanos-intelectualizados que disputavam posições na burocracia do estado. O desenvolvimento do projeto para a criação da primeira instituição universitária em Alagoas pode ser interpretado como exemplar da luta dos grupos urbanos por espaço no interior do estado.

A iniciativa para a criação do projeto da Universidade de Alagoas se deu a partir da reunião de membros das faculdades já existentes sob a regência do professor da Faculdade de Medicina, Aristóteles C. Simões. Em verdade, um conjunto de eventos isolados favoreceu a criação desse grupo de professores. A Faculdade de Direito havia se federalizado e, nessa esteira,

\footnotetext{
2 Outra instituição importante é a Faculdade de Direito, criada em 1933. No entanto, a partir da segunda metade do século XX, esta instituição começa a se integrar à rede de IES que estava se consolidando em Alagoas.
} 


\section{pro.posıções}

$e$-ISSN 1980-6248

http://dx.doi.org/10.1590/1980-6248-2018-0086

a Faculdade de Medicina também almejava tal realização. Isso porque a federalização dessas instituições implicava o custeio, por parte do governo federal, das despesas oriundas da faculdade, das quais a principal era o pagamento dos salários dos professores (Verçosa, 1997). Portanto, o projeto inicial era a federalização da Faculdade de Medicina. No entanto, diante da frustração deste projeto e da demanda da União pela criação de novas universidades ${ }^{3}$, um grupo diferente de professores de faculdades isoladas se formou para a elaboração do projeto de criação da Universidade de Alagoas. Esse projeto contou com o apoio da bancada parlamentar alagoana, tanto na Câmara dos Deputados quanto no Senado Federal, fazendo as mediações políticas necessárias para a aprovação do projeto, de maneira que em 1961 viria a ser sancionado o decreto presidencial de criação da referida instituição.

Ainda que criada, a instituição universitária daquele período, no Brasil em geral, mas em Alagoas em particular, estava primordialmente direcionada para a dimensão de formação de profissionais diplomados. Isso porque o campo de desenvolvimento de pesquisa era precário ou inexistente no país.

Esse elemento atravessou a Universidade de Alagoas durante, pelo menos, 30 anos. Curiosas a esse respeito são as informações acerca da formação dos professores que faziam parte do quadro docente da instituição: no início da década de 1970, 330 professores com curso de graduação, 38 com curso de especialização e 2 com mestrado (Azevedo, 1982); em 1990, eram 579 professores graduados ou especialistas, 344 mestres, 49 doutores e 10 pesquisadores com pós-doutorado (Verçosa \& Cavalcante, 2011). Dessa forma, uma rápida virada na titulação do corpo docente da única universidade em Alagoas, no intervalo de 30 anos, mostra o quanto essa instituição se adaptou ao desenvolvimento da pesquisa através dos seus professores. Ainda importante é observar, em 1990, a existência de 215 projetos de pesquisa cadastrados na Pró-Reitoria de Pesquisa e Pós-Graduação (Verçosa \& Cavalcante, 2011).

É apenas no início do século XXI que o cenário para o desenvolvimento da pesquisa, em Alagoas, se desenvolve e se diversifica. Mais adiante será possível observar esse desenvolvimento a partir dos grupos de pesquisa. Ao observar o quadro docente da

\footnotetext{
${ }^{3}$ Um traço fundamental na criação das novas universidades era a aglutinação de faculdades isoladas, o que diminuía os custos da União ao mesmo tempo que ampliava o acesso ao curso superior. Podemos observar, em 1964, a criação de 39 universidades (inclusa a Universidade de Alagoas).
} 


\section{pro.posıções}

http://dx.doi.org/10.1590/1980-6248-2018-0086

\section{$e$-ISSN 1980-6248}

Universidade Federal de Alagoas (Ufal), em 2010, nota-se que 710 de seus professores possuíam doutorado, 568 eram mestres, e 142 graduados ou especialistas (Verçosa \& Cavalcante, 2011).

Esta síntese histórica visa destacar alguns elementos que permitem caracterizar o campo de produção e desenvolvimento científico em Alagoas. O principal deles tem conexão com o desenvolvimento da ciência no país e sua relação com o Ensino Superior. Se o Ensino Superior no Brasil tem se direcionado prioritariamente para a dimensão do ensino, ou nas palavras de Bourdieu (2011) a respeito das instituições francesas, se "encarregado de transmitir a cultura legítima e por isso investida de uma função social de consagração e de conservação" (p. 104), este é o lastro social através do qual vai se diferenciando seu inventário de atividades. É possível observar o processo de diferenciação das "funções sociais da universidade", principalmente a partir da segunda metade do século XX. Entre as direções assumidas por esse processo, destaca-se aqui o desenvolvimento da ciência através do fomento às pós-graduações.

Em Alagoas, o desenvolvimento da pós-graduação stricto sensu tem início em finais dos anos 1980 com a abertura de um mestrado em Letras e Linguística na Ufal. Mas é somente no princípio dos anos 2000 que este processo se acelera com a abertura de 13 programas de mestrado e 3 de doutorado.

Sua relação mais estreita com o desenvolvimento institucional da Ufal se dá até os dias atuais. Apesar de no início desse século a comunidade acadêmica alagoana ter se diferenciado e se ampliado institucionalmente para além da Ufal, como será demonstrado mais adiante, esta universidade tem grande peso na formatação da comunidade acadêmica. Nesse sentido, esta breve reconstrução sócio-histórica das condições que possibilitaram, no cenário alagoano, a construção e o consequente desenvolvimento do Ensino Superior e, com ele, de uma comunidade de pesquisadores, produtores e consumidores dos produtos científicos e acadêmicos, nos auxilia a compreender dois elementos cruciais que balizarão os próximos tópicos deste texto, nomeadamente: o caráter recente tanto do incremento do número de professores doutores no estado quanto da criação dos programas de pós-graduação; e o papel da Ufal e seu pioneirismo no âmbito da investigação, não esquecendo sua condição institucional de universidade, a qual traz a pesquisa como um de seus pilares. 


\section{pro.posições}

http://dx.doi.org/10.1590/1980-6248-2018-0086

$e$-ISSN 1980-6248

\section{Mapeamento longitudinal dos grupos de pesquisa de Alagoas: expressões institucional e disciplinar da comunidade científica}

A constituição de um grupo de pesquisa - ao implicar condições institucionais, da reunião de recursos humanos e objetivos e, também, de governança no âmbito da ciência e tecnologia - é reveladora de um conjunto complexo de fatores de possibilidade, o qual possui inexoravelmente lastro histórico, como demonstramos até o momento no caso alagoano. Se as IES, os programas de pós-graduação e a atração crescente de professores com titulação de doutorado são elementos-chave para compreender a construção e consolidação da comunidade científica em Alagoas, servimo-nos, pois, destes mesmos elementos para pensar localmente uma instância significativa quando se analisa qualquer comunidade de cientistas: os grupos de pesquisa.

Entre 2000 e 2016, o número de grupos de pesquisa no estado de Alagoas experimentou um crescimento que ultrapassa os 600\%: estamos a falar de um salto de 67 grupos registrados no CNPq no ano 2000 para 517 em 2016. Este primeiro dado demonstra a aceleração do processo de constituição de grupos de pesquisa no estado, em especial se atentarmos para o fato de que a última década (2006-2016) compreende o intervalo no qual é possível observar um crescimento de maior amplitude.

Tendo em vista estes números iniciais, faz-se mister levar em consideração o fato de a comunidade científica de Alagoas ter sua trajetória de constituição e fortalecimento intrinsecamente ligada às histórias das IES e aos sujeitos que compõem este nível de ensino no estado. Nesse sentido, quando tratamos dos grupos de pesquisa enquanto objeto de estudo, estamos a falar dos processos de amadurecimento de tais instituições e de seus corpos docentes, discentes e técnicos no que tange às práticas da pesquisa acadêmica, da formação de novos pesquisadores e do diálogo com a comunidade alagoana - este último ganha sentido quando se toma a investigação como uma das formas de se compreender fenômenos sócio-historicamente localizados e de responder a tais fenômenos e às problemáticas que deles emergem.

Isto significa afirmar que, ao realizarmos o mapeamento institucional e disciplinar dos grupos de pesquisa do estado, tratamos não somente de evidenciar a atuação das IES na esfera da produção de conhecimento, mas também as próprias transformações recentes na estrutura e na configuração do Ensino Superior em Alagoas. 


\section{pro.posições}

$e$-ISSN 1980-6248

http://dx.doi.org/10.1590/1980-6248-2018-0086

A primeira categoria a ser explorada exemplifica esta correlação entre comunidade científica (espaço específico) e Ensino Superior (campo lato). Trata-se da dependência administrativa procedente dos grupos de pesquisa (Gráfico 1):

\section{Gráfico 1 - Dependência administrativa dos grupos de pesquisa alagoanos - percentual ponderado entre 2000 e 2016}

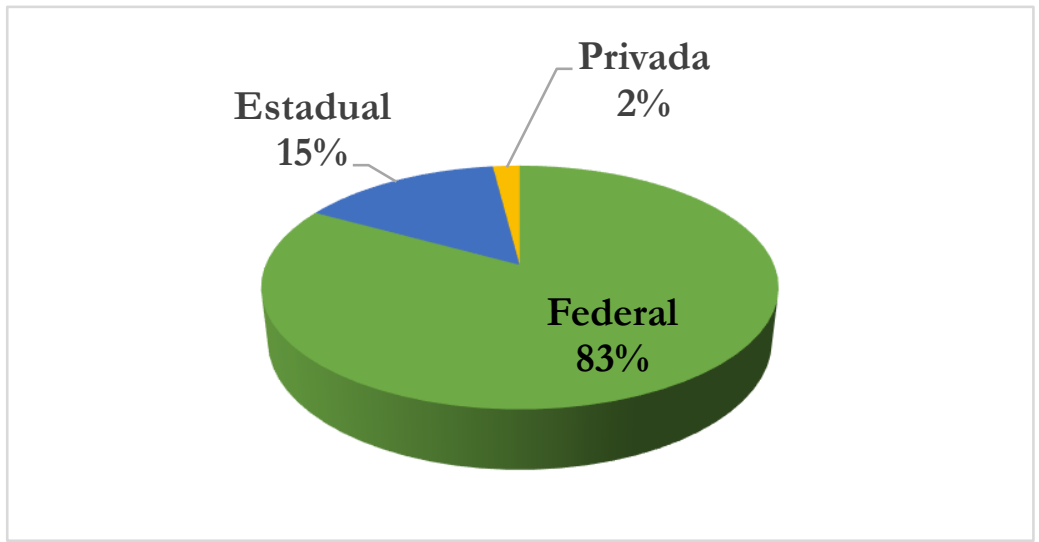

Fonte: elaborado a partir do DGP/CNPq (2017).

A expressividade das instituições públicas no quesito dos grupos de pesquisa em Alagoas evidencia-se no Gráfico 1, a partir do qual é possível assinalar que 98\% destes grupos foram gestados em IES públicas - a divisão desta porcentagem entre as instâncias federal e estadual é ainda capaz de demonstrar a força da primeira no que tange ao desenvolvimento de espaços próprios de produção de conhecimento e de formação de novos pesquisadores. Mas, afinal, o que explica esta hegemonia do setor público em detrimento do privado, em especial em um contexto de histórico "caráter privado da dependência administrativa" do nosso Ensino Superior (Severino, 2008)?

A relação entre público e privado neste espaço, que aparentemente poderia se colocar como uma contradição, é reveladora, na verdade, da divisão do trabalho acadêmico que tem se ratificado historicamente no Brasil. De um lado, no âmbito legal ${ }^{4}$, a diversidade de tipos de IES nos coloca diante de diferentes papéis educacionais e sociais a serem desempenhados pelas instituições. Neves (2002), ao sintetizar a tipologia das IES, aponta dois grandes grupos - as instituições universitárias e as instituições não universitárias -, no interior dos quais temos ainda uma gradação de estabelecimentos de ensino de naturezas distintas. As diferentes finalidades

\footnotetext{
${ }^{4}$ No âmbito da legislação, é possível observar esta diversidade na Lei de Diretrizes e Bases (Lei no 9.394/1996) e no Decreto $n^{\circ} 5.773 / 2006$.
} 


\section{pro.posıções}

$e$-ISSN 1980-6248

http://dx.doi.org/10.1590/1980-6248-2018-0086

implicam, portanto, inclusão e exclusão de atividades acadêmicas específicas: se o ensino e a formação dos estudantes perpassam todas as IES, ações como a pesquisa e a extensão são desenvolvidas por uma parcela particular delas.

Já de outro lado, no âmbito da composição percentual, temos o seguinte cenário no país: de acordo com o Censo do Ensino Superior de 2016 (Instituto Nacional de Estudos e Pesquisas Educacionais Anísio Teixeira, 2017), 87,7\% das instituições deste grau de ensino são privadas e destas $95,7 \%$ são do tipo faculdade ou centro universitário, contra 4,3\% de universidades. Tais números são importantes porque nos falam sobre dois elementos cruciais para o nosso debate. Primeiro, da predominância do setor privado em meio ao público no cenário do Ensino Superior, em nível quantitativo de estabelecimentos e de matrículas, o que se transforma completamente quando o tema são atividades ligadas à pesquisa e à extensão, por exemplo. Segundo, dos tipos de instituições que figuram no interior do setor privado, as quais não possuem obrigação de desenvolver atividades de pesquisa, conforme legislação pertinente (Neves, 2002).

Estamos diante de um quadro que se repete no Nordeste, e mais particularmente em Alagoas, com percentuais variados: o censo de 2016 revelou que na região nordeste foram contabilizados 1.444.368 alunos matriculados no Ensino Superior, dos quais 62\% estão em instituições privadas e 38\% em públicas. No caso de Alagoas, cujo total de matrículas chegou a 77.738 , o documento mostra que $60 \%$ dos estudantes se encontram no setor privado, enquanto 40\% estão no público (Instituto Nacional de Estudos e Pesquisas Educacionais Anísio Teixeira, 2017).

Apesar de as IES privadas figurarem com dominância numérica, em âmbito nacional, regional e local, a divisão do trabalho acadêmico que se coloca na materialidade do Ensino Superior no país acaba por colocar as IES públicas em posição dominante no que tange ao terreno da pesquisa. Esta questão se expressa por meio de instâncias como os programas de pós-graduação (Velloso, 2004), os grupos de pesquisa, as associações de investigação ou mesmo os periódicos especializados, que se encontram alocados sobretudo no setor público.

No caso do estado de Alagoas, é possível avançar na análise e aprofundar a caracterização em torno do aspecto institucional pelo detalhamento das IES de filiação dos grupos de pesquisa. O Gráfico 2 traz uma descrição desta categoria em relação ao tempo. 


\section{pro.posıções}

$e$-ISSN 1980-6248

Gráfico 2 - Instituições de filiação dos grupos de pesquisa alagoanos, 2000-2016

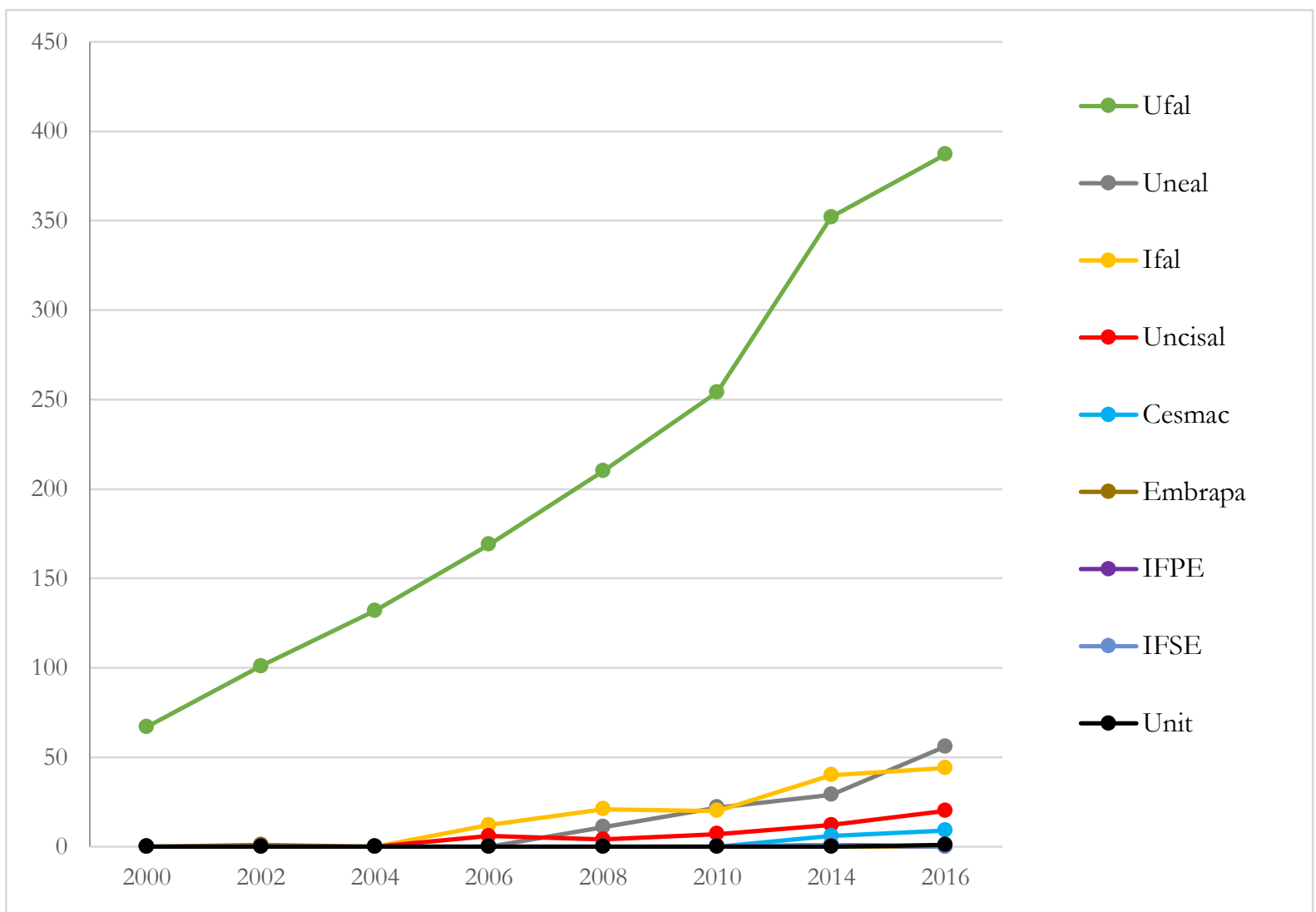

Ufal: Universidade Federal de Alagoas; Uneal: Universidade Estadual de Alagoas; Ifal: Instituto Federal de Alagoas; Uncisal: Universidade Estadual de Ciências da Saúde de Alagoas; Cesmac: Centro Universitário Cesmac; Embrapa: Empresa Brasileira de Pesquisa Agropecuária; IFPE: Instituto Federal de Educação, Ciência e Tecnologia de Pernambuco; IFSE: Instituto Federal de Educação, Ciência e Tecnologia de Sergipe; Unit: Centro Universitário Tiradentes.

Fonte: elaborado a partir do DGP/CNPq (2017).

A expressividade das IES públicas, já revelada no Gráfico 1, é aqui corroborada pela hegemonia da Ufal, que apresenta uma taxa de crescimento de aproximadamente $477 \%$ no período apresentado no Gráfico 2, assim como pelo crescimento do número de grupos de pesquisa nas demais instituições públicas do estado. Destaca-se, nesse sentido, o aumento do número de doutores entre os anos 2000 e 2016. Enquanto em 2000 os professores com título de doutor somavam 710, em 2016 esse número sobe para 1.015 (Instituto Nacional de Estudos e Pesquisas Educacionais Anísio Teixeira, 2017).

O caso da Ufal deve ser compreendido no âmbito das atribuições, históricas e legais, destinadas às IES classificadas como universidades. Esta questão ganha sentido quando se observa a diversificação dos tipos de IES que compõem este grau de ensino no Brasil - de 


\section{pro.posıções}

$e$-ISSN 1980-6248

http://dx.doi.org/10.1590/1980-6248-2018-0086

universidades a faculdades isoladas, passando pelos centros universitários e pelas instituições não universitárias - e, sobretudo, quando se atenta para o fato de que as universidades são instituições pluridisciplinares, caracterizadas pela indissociabilidade entre as frentes de ensino, pesquisa e extensão, além de contarem com um quadro docente marcado pela presença de mestres e doutores em regime de trabalho integral (Neves, 2003). Nesse sentido, a correlação entre o aumento do número de docentes e o aumento dos grupos de pesquisa em um mesmo período temporal ganha potencial explicativo para se entender a atuação de um profissional que passa a compor uma instituição que historicamente tem a pesquisa como uma de suas funções sociais.

Tal incremento no sentido dos doutorados, como era de se esperar, não foi um movimento endêmico ao estado de Alagoas, tampouco à UFAL, posto que o aumento dos cursos de graduação e pós-graduação no país foi defendido como uma das saídas para a problemática dos excedentes, ou seja, a falta de vagas nas universidades (Alves \& Oliveira, 2014); o país atravessou um alargamento da atenção dada à ciência e à formação nos mais altos graus nas últimas décadas; e o aumento da população de mestres e doutores no Brasil é um indicativo dos esforços do sistema de pós-graduação (Centro de Gestão e Estudos Estratégicos, 2016). No caso da Ufal, um dos fatores que contribuiu para esse incremento é, sem dúvida, o Programa de Apoio a Planos de Reestruturação e Expansão das Universidades Federais (Reuni) e, para além disso, pode-se aventar como elementos explicativos: (i) o crescimento dos movimentos de "migração interna" de mestres e doutores no Brasil (Avellar, 2014), com especial atenção para as instituições do Norte e do Nordeste brasileiro; e (ii) as dificuldades de alocação de doutores em suas respectivas cidades de origem e de formação, a partir de uma inflação dos diplomas, da relação entre contingente formado e demanda de colocações profissionais etc.

O Reuni foi um programa de apoio à expansão das universidades federais brasileiras iniciado em 2003 com o processo de interiorização dos campi destas instituições ${ }^{5}$. No entanto, apenas em 2007 o programa ganhou seu formato final, através da publicação do Decreto $\mathrm{n}^{\mathrm{o}}$ 6.096, de 24 de abril de 2007. Este documento contém as diretrizes que normatizaram a criação dos planos de reestruturação pelas universidades federais. Entre as metas do Reuni,

\footnotetext{
${ }^{5}$ Segundo os dados oficiais do Ministério da Educação ("O que é”, 2010), o protótipo do Reuni se inicia com o plano de expansão das universidades, em 2003, através da interiorização, ou seja, com a expansão física, acadêmica e pedagógica para cidades interioranas. Somente em 2007 o Reuni foi instituído através de uma Medida Provisória e integrou o Plano de Desenvolvimento da Educação.
} 


\section{pro.posıções}

http://dx.doi.org/10.1590/1980-6248-2018-0086

\section{$e$-ISSN 1980-6248}

destacamos o aumento de vagas de ingresso de estudantes. Por conseguinte, no documento, podemos ler:

O Ministério da Educação destinará ao Programa recursos financeiros, que serão reservados a cada universidade federal, na medida da elaboração e apresentação dos respectivos planos de reestruturação, a fim de suportar as despesas decorrentes das iniciativas propostas, especialmente no que respeita a:

$\cdots$

III- despesas de custeio e pessoal associadas à expansão das atividades decorrentes do plano de reestruturação ("Decreto no 6.096", 2007).

A elaboração e execução do plano de expansão da Ufal permitiu a ampliação do seu quadro docente. Nesse sentido, os indicadores de crescimento dos grupos de pesquisa nessa instituição têm relação com a ampliação do investimento em concursos para professores universitários.

Outro elemento importante foi a Medida Provisória no 614, de 14 maio de 2013, que exigiu o título de doutor para contratação de professores de universidades e institutos federais. $\mathrm{Na}$ prática, essa medida provisória não anulou a contratação de professores com o título de mestrado, no entanto, privilegiou, nos processos de seleção para ingresso na carreira de docente, os professores que possuíam o título de doutor. Seguramente a publicação dessa medida provisória tem relação com o aumento dos grupos de pesquisa, pois, somada ao Reuni, representou a contratação de mais professores doutores com regime de trabalho de "tempo integral", ou seja, que devem, no desempenho de suas funções docentes, dedicar-se ao desenvolvimento de atividades de ensino, pesquisa e extensão.

Logo depois da Ufal, os destaques vão para: a Universidade Estadual de Alagoas (Uneal), que somente começa a apresentar grupos a partir de 2008, o que é totalmente compreensível dada a sua criação recente - seu processo de estadualização data de 1995 e sua passagem a universidade data de 2006 (Aragão, 2010); seguida do Instituto Federal de Alagoas (Ifal), que entre 2006 e 2016 apresentou um crescimento significativo, saindo de 12 para 44 grupos de pesquisa em uma década; e da Universidade Estadual de Ciências da Saúde de Alagoas (Uncisal), que igualmente passou a contar com grupos de pesquisa cadastrados no CNPq a partir de 2006 e mais que triplicou o número no intervalo em questão.

Ainda na esfera pública, Alagoas contou, ao longo destes anos, com grupos filiados a outras instituições de forma mais interrupta, nomeadamente: a Empresa Brasileira de Pesquisa 


\section{pro.posições}

http://dx.doi.org/10.1590/1980-6248-2018-0086

\section{$e$-ISSN 1980-6248}

Agropecuária (Embrapa), que aparece com um grupo em 2002; e o Instituto Federal de Pernambuco (Ifpe) e o Instituto Federal de Sergipe (IFSE), que aparecem cada um com um grupo de pesquisa no ano de 2014.

Já no âmbito das instituições privadas, os grupos de pesquisa, além de escassos numericamente falando, somente foram criados (ou ao menos registrados no $\mathrm{CNPq}$ ) há poucos anos. O Centro Universitário Cesmac figura com grupos a partir de 2014, passando de seis neste ano para nove em 2016. E o Centro Universitário Tiradentes (Unit) passou a aparecer com um grupo de pesquisa em 2016. Se partirmos do enquadramento legal como ponto de referência para compreender a expressividade representada por estas duas instituições privadas no estado de Alagoas, no que tange aos grupos de pesquisa, o fato de elas se constituírem como centros universitários pode nos auxiliar a associar sua natureza com a não obrigatoriedade de desenvolvimento de atividades de investigação - questão criticada e discutida por alguns pesquisadores, como Severino (2008) e Soczec \& Alencastro (2012).

Florêncio (2007) demonstra que o estado de Alagoas, ao avançar na melhoria de seus índices educacionais nas últimas décadas, em especial na formação ao nível de Ensino Médio, permitiu a criação das condições de atração de investimentos da iniciativa privada voltados para o Ensino Superior. No período posterior à Lei de Diretrizes e Bases da Educação Nacional, de 1996, este estado acabou por experienciar uma expansão do Ensino Superior privado, que passou a atender uma boa parcela da população cuja escolarização começou a ser incrementada. Naturalmente, como assinalaram Silva Jr. \& Sguissardi (2001), a expansão do Ensino Superior privado no país, com raras exceções, abandona o modelo que integra ensino, pesquisa e extensão por uma questão de simples relação entre investimento e retorno financeiro.

Nesse sentido, o crescimento, expansão e a diversificação do Ensino Superior em Alagoas, guardadas as devidas especificidades históricas, ratificaram a divisão do trabalho acadêmico entre instituições públicas e privadas, o que pode ser observado no caso do presente estudo pela frente representada pela pesquisa.

O paralelismo entre expansão e diversificação e sua expressão nos grupos de pesquisa não ficam restritos às instituições. Podemos observá-lo ainda nas áreas do conhecimento e no seu comportamento ao longo dos anos, por um lado, e a partir do número de sujeitos envolvidos nos grupos, por outro. Isso significa dizer que o incremento no número de grupos de pesquisa, bem como de IES que servem como espaço de criação, acreditação e desenvolvimento destes 


\section{pro.posições}

$e$-ISSN 1980-6248

grupos, é diretamente proporcional ao avolumamento dos pesquisadores no estado de Alagoas e das linhas de pesquisa e respectivas áreas do conhecimento às quais eles se dedicam.

Gráfico 3 - Áreas do conhecimento dos grupos de pesquisa de Alagoas - variação 2000-2016

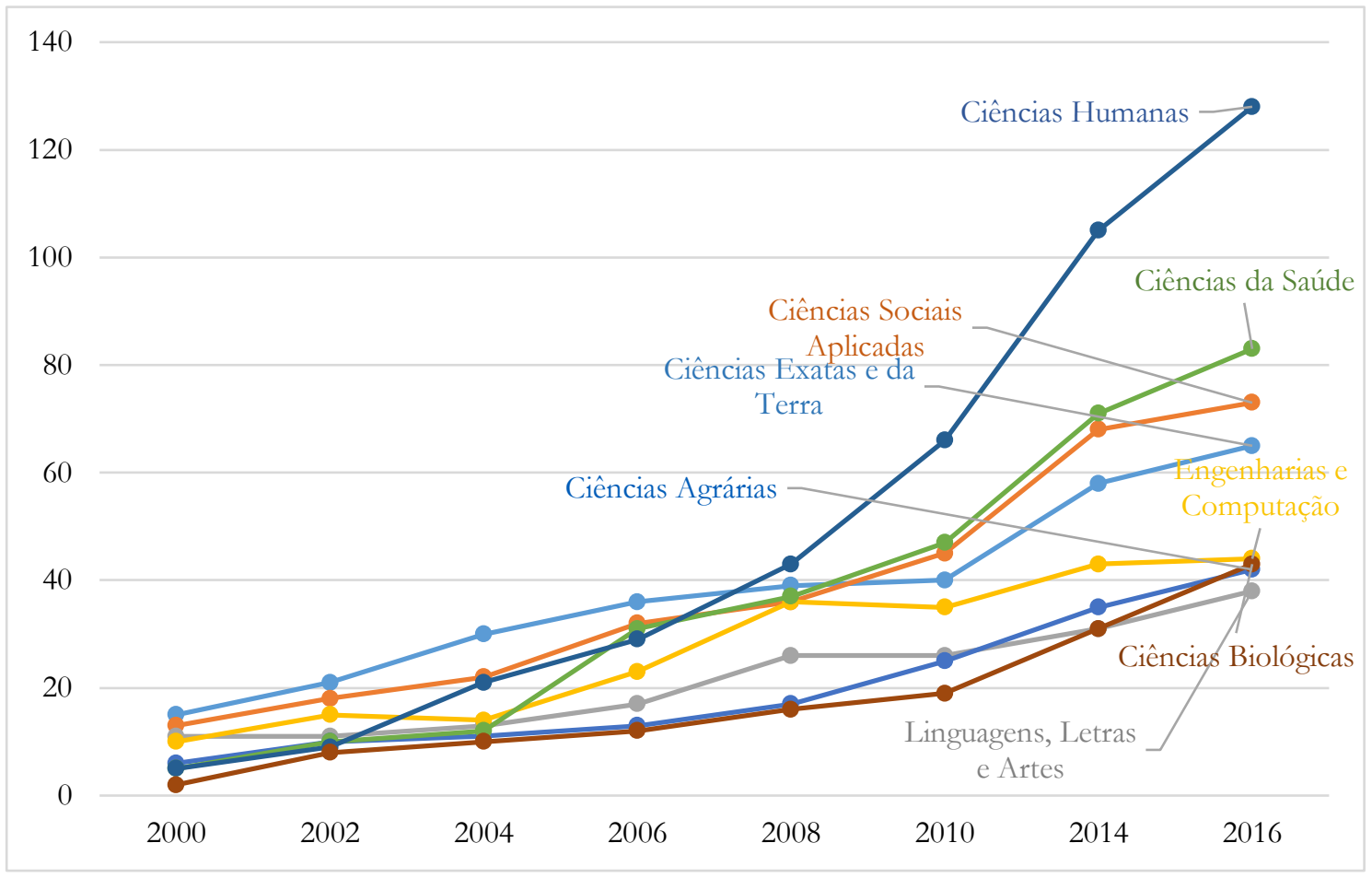

Fonte: elaborado a partir do DGP/CNPq (2017).

O Gráfico 3 evidencia uma evolução numérica significativa em todas as áreas do conhecimento, além de uma transformação na sua disposição. Se em 2000 as Ciências Exatas e da Terra figuravam com destaque no cenário alagoano, com $23 \%$ dos grupos de pesquisa daquele ano (o que equivale, neste período, a 15 grupos), em 16 anos assistimos a algumas transformações. O maior crescimento apontado diz respeito às Ciências Humanas, que passaram de 5 grupos em 2000 para 128 no ano de 2016, crescimento que permitiu a esta área passar a comportar o maior número de grupos de pesquisa do estado desde 2008. Se tomarmos o interior das Ciências Humanas na análise, teremos que a área da Educação ${ }^{6}$ possui preponderância neste cenário de eclosão de grupos, seguida de Geografia, História, Sociologia e Psicologia.

\footnotetext{
${ }^{6}$ Podemos compreender este crescimento dos grupos de pesquisa na área da Educação em tendência nacional, apontada por Silva (2017) como uma das consequências do processo de autonomização universitária desta área do conhecimento.
} 


\section{pro.posições}

http://dx.doi.org/10.1590/1980-6248-2018-0086

\section{$e$-ISSN 1980-6248}

Destacamos ainda as Ciências da Saúde que, como a Educação, apareciam com 5 grupos nos anos 2000 e, em 2016, já figuravam com 83 grupos, destacando-se como segunda área em número de grupos de pesquisa no estado de Alagoas no cenário recente. Além dessas áreas, vale a pena apontar o crescimento constante das áreas de Ciências Sociais Aplicadas, bem como das Ciências Exatas e da Terra e das Engenharias e Computação; as Ciências Biológicas saltaram de apenas 2 grupos em 2000 para 43 em 2016, e as Ciências Agrárias, em um movimento semelhante, saíram de 6 grupos de pesquisa em 2000 e para 42 em 2016; por fim, a área de Linguagens, Letras e Artes aparecem com um movimento mais tímido ao longo deste período, passando de 11 grupos nos anos 2000 para 38 em 2016.

Diante destes números, importa-nos acentuar a diversificação de áreas e linhas de pesquisa que o cenário alagoano passou a experimentar a partir da expansão de seu Ensino Superior e, consequentemente, de seus grupos de pesquisa. As distâncias numéricas entre as áreas, por sua vez, são reveladoras, de um lado, dos caminhos e especificidades sócio-históricas que as IES alagoanas têm construído e, de outro, de como as disputas no jogo acadêmico têm tomado corpo neste contexto sob o escopo de cada área do conhecimento - uma vez que estas áreas se encontram em relação de disputa por inúmeros recursos e capitais científicos (Bourdieu, 2008).

A última expressão da consolidação dos grupos de pesquisa e da comunidade científica em Alagoas é aqui dada pelos sujeitos. Naturalmente, após caracterizarmos os números absolutos, as instituições e suas dependências administrativas e ainda as áreas do conhecimento, evidencia-se que estamos, concomitantemente, a tratar de um crescimento de pessoas no cenário da pesquisa neste estado. Como argumentamos no início deste artigo, a expansão e diversificação do Ensino Superior acarretou, entre outras questões, a necessidade de formação de novos quadros para este grau de ensino. Neste sentido, e sendo a pesquisa e a pós-graduação instâncias importantes neste tipo específico de formação, é de se esperar um número cada vez maior de sujeitos envolvidos com a prática de pesquisa nas universidades nos últimos anos, o que se relaciona com a democratização deste espaço e também com a difusão cada vez mais ampla do ofício de pesquisador no Brasil.

No período de 16 anos que estamos a analisar (2000-2016), o número de pesquisadores em Alagoas cadastrados nos grupos do diretório do CNPq passou de 256 para 3.081, o que sintetiza um crescimento exponencial do número de professores/pesquisadores e reflete a 


\section{pro.posições}

$e$-ISSN 1980-6248

http://dx.doi.org/10.1590/1980-6248-2018-0086

divisão em áreas do conhecimento da qual tratamos anteriormente. Quando nos detemos aos estudantes que compõem estes grupos, a taxa de crescimento é ainda mais surpreendente: Alagoas passou de 377 estudantes cadastrados em grupos de pesquisa no ano 2000 para 6.309 em 2016. Destacam-se ainda, no âmbito dos sujeitos partícipes dos grupos de pesquisa, os técnicos e os colaboradores estrangeiros: entre 2000 e 2016, o número de técnicos nestes grupos passou de 40 para 141; e entre 2014 e 2016, o CNPq registrou um aumento de 20 para 31 pesquisadores estrangeiros que participam como colaboradores dos grupos de pesquisa de Alagoas.

No caso dos docentes/pesquisadores, há que se apontar os seguintes fatores relativos ao contexto alagoano: a consolidação e recente expansão da Ufal e a consequente atração de sujeitos vindos inclusive de outros estados; a renovação dos quadros possibilitada pelo estabelecimento dos programas de pós-graduação stricto sensu no estado nas últimas duas décadas; e a institucionalização da prática de pesquisa nas IES do estado. E, no âmbito dos estudantes, faz-se mister compreender esta evolução numérica no quadro de expansão das universidades alagoanas e da consequente diversificação do seu público (Lopes, 2015).

Em síntese, o exercício de caracterizar a comunidade científica de Alagoas por meio de seus grupos de pesquisa nos levou a compreender o papel decisivo da Ufal como instituição que condensa em si atividades de produção, difusão e consumo dos conhecimentos produzidos por sua comunidade científica. A expansão do Ensino Superior vivenciada no Brasil em geral, e de forma particularizada em seus estados, serviu de pano de fundo para a instituição de novos grupos de pesquisa no caso alagoano, bem como para a consolidação dos já existentes, o que nos remete a uma conjuntura de desenvolvimento e consolidação do quadro de pesquisadores no estado e, em consequência disso, da sua própria comunidade acadêmica.

\section{Considerações finais}

A tarefa de objetivar a comunidade científica no contexto alagoano permitiu-nos promover uma correlação entre fenômenos mais amplos ligados à expansão e à diversificação do Ensino Superior no Brasil e os processos mais específicos de aperfeiçoamento dos espaços de desenvolvimento de pesquisa e formação de novos pesquisadores no estado. Esta correlação encontra suas condições de possibilidade no incremento numérico de instituições e sujeitos 


\section{pro.posıções}

http://dx.doi.org/10.1590/1980-6248-2018-0086

\section{$e$-ISSN 1980-6248}

acarretado pelo alargamento deste grau de ensino, fato que acabou por estimular as diferentes frentes que marcam a atuação das IES no país - ensino, pesquisa e extensão.

Articular, nesse sentido, os processos de expansão deste grau de ensino ao desenvolvimento de uma esfera cada vez mais autonomizada e consolidada no interior do âmbito universitário, aqui denominada de comunidade científica, parece-nos fundamental pela amplitude relacional que este movimento acaba por possibilitar. Do ponto de vista analítico, promove um alargamento dos objetos de estudo ligados ao tema da ampliação e diversificação do Ensino Superior que o Brasil vive no cenário recente, ao passo que revela a constelação de elementos sobre os quais as transformações acarretadas por tal ampliação incidem. Além disso, esta abordagem evidencia as interseções que marcam as frentes de ensino, pesquisa e extensão no contexto universitário, posto que movimentos como o incremento de vagas, novos cursos, novos docentes, novas IES e o processo de interiorização estendem-se e modificam o próprio campo científico brasileiro.

Estas assertivas mais gerais amparam o olhar aqui lançado para o caso do estado de Alagoas. No que tange às especificidades da experiência alagoana, sua história recente de construção de um aparato institucional e de recursos humanos para o Ensino Superior mostrou-se determinante para as condições de efetivação de uma comunidade científica, expressa, entre outros espaços, nos grupos de pesquisa. Na relação nacional-local, temos as políticas públicas para o Ensino Superior público federal com peso relativamente forte para o fortalecimento da comunidade científica do estado, porque a Ufal figura com um volume bastante superior de grupos de pesquisa, como vimos ao longo do texto, e o IFAL também se destaca neste quesito.

O Reuni pode ser citado, sem nos esquecermos das críticas apontadas na literatura (Filardi, 2014), como um exemplo de política que promoveu uma reconfiguração, entre outros setores, no âmbito da pesquisa em Alagoas, uma vez que acabou por permitir a ampliação de vagas, cursos e campi da Ufal, elementos essenciais para a expansão da comunidade científica nesta universidade - este tipo de correlação pode ser observada em Afonso (2014). E, no que tange ao Ifal, pode-se apontar a sua passagem de Centro Federal de Educação Tecnológica para Instituto Federal, a qual, para efeitos de regulação, avaliação e supervisão e da oferta de cursos superiores, equiparou os institutos federais às universidades (Pacheco, Caldas, \& Domingos Sobrinho, 2012), ampliando suas possibilidades no plano da pesquisa e produção de 


\section{pro.posıções}

http://dx.doi.org/10.1590/1980-6248-2018-0086

\section{$e$-ISSN 1980-6248}

conhecimentos. Esta relação entre políticas públicas de expansão do Ensino Superior e a comunidade científica pode constituir, por sua vez, horizonte futuro de investigação.

No âmbito específico da prática de investigação, faz-se mister, ademais, apontar os grupos de pesquisa como um espaço privilegiado de construção de conhecimento e de formação de novos quadros de pesquisadores. A história recente do Ensino Superior no estado de Alagoas tem na pesquisa uma expressão da maturidade e consolidação deste grau de ensino, bem como da sua comunidade científica. Os dados apontados pelo estudo são reveladores dos movimentos de crescimento exponencial desses grupos bem como de sua configuração. Destacam-se, pois: a divisão do trabalho acadêmico entre IES públicas e privadas revelada pelo número de grupos de pesquisa que cada uma delas comporta; o papel das instituições públicas na efetivação de uma comunidade científica alagoana, com especial atenção para a Ufal; a relação entre aumento do número de sujeitos no Ensino Superior e a diversificação institucional e de áreas do conhecimento no âmbito dos grupos de pesquisa; e, ainda, a problemática da descontinuidade dos grupos de pesquisa, sobretudo nas IES privadas.

\section{Referências}

Afonso, M. R. (2014). O impacto do Reuni na pós-graduação: o caso da Universidade Federal de Pelotas. Revista Eventos Pedagógicos, 5(3), 102-116.

Alves, M. F., \& Oliveira, J. F. (2014). Pós-Graduação no Brasil: do Regime Militar aos dias atuais. Revista Brasileira de Política e Administração da Educação, 30(2), 351-376.

Aragão, M. H. M. (2010). Ensino superior na Funesa: contextos e trajetórias (1990-2006). Dissertação de Mestrado, Universidade Federal de Alagoas, Maceió.

Avellar, S. O. C. (2014). Migração interna de mestres e doutores no Brasil: algumas considerações. Revista Brasileira de Pós-Graduação, 11(24), 429-457. doi:10.21713/23582332.2014.v11.512

Azevedo, J. (Org.). (1982). Universidade Federal de Alagoas: documentos históricos. Maceió: Ufal.

Bourdieu, P. (2008). Para uma Sociologia da Ciência. Lisboa: Edições 70.

Bourdieu, P. (2011). Homo academicus. Florianópolis: Ed. UFSC. 


\section{pro.posições}

http://dx.doi.org/10.1590/1980-6248-2018-0086

\section{$e$-ISSN 1980-6248}

Centro de Gestão e Estudos Estratégicos. (2016). Mestres e doutores 2015: estudos da demografia da base técnico-cientifica brasileira. Recuperado de https://www.cgee.org.br/documents/10182/734063/Mestres_Doutores_2015_Vs3.p df

Creswell, J. W. (2012). Educational research: planning, conducting and evaluating quantitative and qualitative research (4a ed.). Boston: Pearson Education.

Decreto $\mathrm{n}^{\mathrm{o}}$ 6.096, de 24 de abril de 2007. (2007, 25 de abril). Institui o Programa de Apoio a Planos de Reestruturação e Expansão das Universidades Federais - REUNI. Diário Oficial da União, seção 1, 7.

Diretório dos Grupos de Pesquisa no Brasil, \& Conselho Nacional de Desenvolvimento Científico e Tecnológico. (2017). Súmula estatística por UF. Recuperado de http://lattes.cnpq.br/web/dgp/por-uf2

Filardi, A. M. B. (2014). Desenvolvimento do Reuni: crítica à sua implantação e sua relação econômica. Linhas críticas, 20(43), 563-582. doi:10.26512/lc.v20i43.4389

Florêncio, T. M. (2007). A expansão do Ensino Superior privado em Alagoas: um panorama pós-LDB. Dissertação de Mestrado, Universidade Federal de Alagoas, Maceió.

Hey, A. P. (2008). Esboço de uma sociologia do campo acadêmico: a Educação Superior no Brasil. São Carlos: EDUFSCar.

Instituto Nacional de Estudos e Pesquisas Educacionais Anísio Teixeira. (2017). Microdados: censo da Eduação $2016 . \quad$ Superior: Recuperado de http://portal.inep.gov.br/web/guest/microdados

Lopes, E. M., \& Lobo, D. A. (2016). Características dos grupos de pesquisa da Universidade Federal do Rio Grande (FURG) cadastrados no Diretório de Grupos de Pesquisa do Brasil (DGP/CNPQ). Biblos, 30(1), 79-101.

Lopes, R. M. (2015). Valorização do Ensino Superior a partir de trajetórias de professores universitários. Dissertação de Mestrado, Universidade Federal de Alagoas, Maceió.

Martins, C. B. (2000). O Ensino Superior brasileiro nos anos 90. São Paulo em Perspectiva, 14(1), 41-60. 


\section{pro.posıções}

$e$-ISSN 1980-6248

http://dx.doi.org/10.1590/1980-6248-2018-0086

Neves, C. E. B. (2002). A estrutura e o funcionamento do Ensino Superior no Brasil. In M. S. A. Soares (Coord.), A Educação Superior no Brasil (pp. 39-112). Porto Alegre: Unesco.

Neves, C. E. B. (2003). Diversificação do sistema de educação terciária: um desafio para o Brasil. Tempo Social, 15(1), 21-44. doi:10.1590/S0103-20702003000100002

O que é o Reuni. (2010). Reuni: Reestruturação e Expansão das Universidades Federais. Recuperado de http://reuni.mec.gov.br/o-que-e-o-reuni

Oliveira, A., \& Silva, C. F. (2014). Mapeando a Sociologia da Educação no Brasil: análise de um campo em construção. Atos de Pesquisa em Educação, 9(2), 289-315. doi:10.7867/18090354.2014v9n2p289-315

Pacheco, E. M., Caldas, L., \& Domingos Sobrinho, M. D. (2012). Institutos federais de educação, ciência e tecnologia: limites e possibilidades. In E. M. Pacheco, \& V. Morigi (Orgs.). Ensino técnico, formação profissional e cidadania: a revolução da educação profissional e tecnológica no Brasil (pp. 15-31). Porto Alegre: Tekne.

Rapini, M. S. (2007). O diretório dos grupos de pesquisa do CNPq e a interação universidadeempresa no Brasil: uma proposta metodológica de investigação. Revista de Economia Contemporânea, 11(1), 99-117. doi:10.1590/S1415-98482007000100004

Severino, A. J. (2008). O Ensino Superior brasileiro: configurações e velhos desafios. Educar, (31), 73-89. doi:10.1590/S0104-40602008000100006

Silva, C. F. (2017). (Ciências da) Educação no Brasil e em Portugal: autonomização dos espaços acadêmicos especificos. Tese de Doutorado, Universidade Nova de Lisboa, Lisboa.

Silva, J. R., Jr., \& Sguissardi, V. (2001). Novas faces da Educação Superior no Brasil: reforma do Estado e mudanças na produção (2a ed.). São Paulo: Cortez.

Soczec, D., \& Alencastro, M. (2012). Pesquisa acadêmica em instituições de Ensino Superior particulares: desafios e perspectivas. Revista Intersaberes, 7(13), 46-66.

Sousa, S. B. (2010). A 'comunidade académica' como um conceito errático. Sociologia: Revista do Departamento de Sociologia da FLUP, 20, 149-166.

Velloso, J. (2004). Mestres e doutores no país: destinos profissionais e políticas de pósgraduação. Cadernos de Pesquisa, 34(123), 583-611. doi:10.1590/S010015742004000300005 


\section{pro.posıções}

$e$-ISSN 1980-6248

Verçosa, E. G. (1997). História do ensino superior em Alagoas: verso e reverso. Maceió: Edufal.

Verçosa, E. G., \& Cavalcante, S. (Orgs.). (2011). Universidade Federal de Alagoas: o livro dos 50 anos. Maceió: Edufal.

Zago, N. (2006). Do acesso à permanência no Ensino Superior: percursos de estudantes universitários de camadas populares. Revista Brasileira de Educação, 11(32), 226-237. doi:10.1590/S1413-24782006000200003

Submetido à avaliação em 09 de agosto de 2018; revisado em 06 de maio de 2019; aceito para publicaşão em 22 de julho de 2019. 